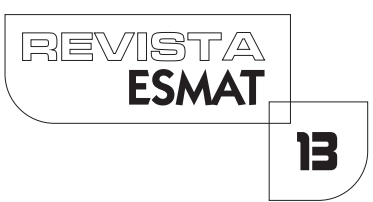

\title{
O PENSAMENTO CULTURALISTA DE A. L. MACHADO NETO: CONTRIBUTOS PARA O EGOLOGISMO JURÍDICO
}

\author{
THE CULTURALIST THINKING OF A. L. MACHADO NETO: \\ CONTRIBUTIONS FOR LEGAL EGOLOGISM
}

Ricardo Maurício Freire Soares

Pós-Doutor em Direito pela Università degli Studi di Roma - La Sapienza e pela Università degli Studi di Roma Tor Vergata. Doutor em Direito pela Università del Salento. Doutor e mestre em Direito pela Universidade Federal da Bahia. Professor da Universidade Federal da Bahia. Professor-Visitante na Università degli Studi Roma Tre, Università Degli Studi di Milano, Università di Genova, Università di Pisa, Universidade Autônoma de Lisboa e Martin-Luther-Universitat. Membro do Instituto dos Advogados Brasileiros e do Instituto dos Advogados da Bahia. Palestrante e autor de diversas obras jurídicas. E-mail: ric.mauricio@ig.com.br

Raissa Pimentel Silva

Doutoranda em Direito Público e mestra em Relações Sociais e Novos Direitos pelo Programa de Pós-Graduação em Direito da Universidade Federal da Bahia (UFBA). Especialista em Direito Imobiliário pela Universidade Salvador (UNIFACS). Professora na Universidade Salvador (UNIFACS). Professora convidada da Universidade Católica do Salvador (CSAL). Professora substituta da Faculdade de Direito da UFBA. E-mail: raissapimentelss@gmail.com

\section{RESUMO}

A Teoria Egológica do Direito, de lavra do argentino Carlos Cossio, surgida no seio dos movimentos pós-positivistas, encontrou no jus filósofo baiano A. L. Machado Neto um dos seus maiores defensores e propagadores no orbe jurídico-acadêmico brasileiro. A partir da averbação de referências resultantes de pesquisa bibliográfica, historiográfica e documental, o presente escrito foi elaborado com o intuito de arregimentar as contribuições aditadas por A. L. Machado Neto à teoria do Direito. À guisa de atingir esse desiderato, serão consignadas, em caráter preparatório, as ideias nucleares que permeiam o egologismo jurídico, nos moldes propostos pelo seu precursor argentino, posicionando-o no contexto do culturalismo jurídico, bem como registradas as nuances da vida e obra do jusfilósofo baiano aqui reverenciado.

PALAVRAS-CHAVE: A. L. Machado Neto; Culturalismo jurídico; Egologismo jurídico; Teoria egológica do direito. 


\begin{abstract}
The Egological Theory of Law, proposed by the argentinean Carlos Cossio, emerged within the post-positivist movement, found in A.L. Machado Neto one of its greatest advocates and propagators in the brazilian academic and juridical sphere. From the registration of references resulting from literature, historiography and documentary research, this writing was developed in order to enlist the contributions added by $A$. L. Machado Neto to the theory of law. By way of achieving this goal, shall be included in preparatory character, the core ideas that permeate the legal egologism, as proposed by its argentinean precursor, placing it in the context of legal culturalism, and the nuances of the life and work of the bahian jus philosopher revered here.
\end{abstract}

KEYWORDS: A.L. Machado Neto; Legal culturalism; Legal egologism; Egological theory of law.

mestre é aquele que ultrapassou a concepção de uma verdade como fórmula universal, solução e resolução do ser humano, para se elevar à idéia de uma verdade como procura.

O mestre quer ser antes de tudo iniciador da cultura. A cultura não é outra coisa senão a tomada de consciência, por cada indivíduo, dessa verdade que fará dele um homem.

Ele é, no entanto, o operador de uma experiência iniciática. Graças a ele o espírito dirige-se ao espírito sem qualquer poder senão o do espírito.

GUSDORF, Georges. Professores, para quê? Lisboa, Morais, 1970.

\title{
I INTRODUÇÃO
}

O presente artigo foi concebido com o escopo de revisitar a biografia do jurisfilósofo baiano Antônio Luiz Machado Neto, mestre na mais pura acepção do termo, conferindo especial enfoque a uma das suas mais relevantes contribuições ao pensamento jurídico, qual seja, a difusão e aprimoramento, em solo pátrio, da teoria egológica do direito, preconizada pelo argentino Carlos Cossio, no contexto dos movimentos póspositivistas.

Para melhor compreensão do leitor, os temas que compõem o presente trabalho encontram-se organizados em três tópicos distintos. A porta de entrada para a tarefa ora empreendida será um sobrevoo por sua vida, destacando-se os seus principais feitos. Em seguida, far-se-á uma breve exposição dos argumentos apresentados pelo referido autor argentino, a fim de justificar a sedimentação da teoria egológica como alternativa a 
até então tradicional teoria positivista, de matriz kelseniana. Por fim, passar-se-á à análise da interpretação conferida por Machado Neto às bases teóricas do egologismo jurídico lançadas por Cossio, destacando-se as principais considerações aditadas pelo teórico baiano.

Há de ser registrado, de plano, que o presente trabalho não ambiciona esgotar a análise da fecunda produção intelectual de A. L. Machado Neto, mas apenas retratar, em curtas linhas, a relevância das suas contribuições ao universo jurídico-acadêmico, fornecendo condições para que as suas ideias possam continuar reverberando.

\section{BIOGRAFIA}

Em 12 de junho de 1930, nascia, em Salvador, Antônio Luiz Machado Neto. O garoto que em tenra idade tornou-se refém de uma ascite aguda que lhe impôs uma reclusão por quatro longos anos de sua infância aprendeu a cultivar desde cedo o hábito da leitura e a exercitar a imaginação crítico-criativa.

O apreço pela leitura naturalmente o conduziu, já na adolescência, ao estudo de teoria literária, crítica de arte e estética, por ocasião da sua passagem pelo renomado Colégio da Bahia, disciplinas que prepararam o caminho para a sua imersão nos domínios dos saberes teóricos, em especial a Filosofia, a Sociologia e a Política, após o seu ingresso, em 1950, aos dezenove anos, no corpo discente da Faculdade de Direito da Universidade Federal da Bahia, tendo obtido a primeira colocação no exame vestibular para ingresso (Neto, 1979).

A sua carreira acadêmica - e, por certo, a sua descoberta vocacional - começou a ser cunhada de modo ímpar já nos primeiros meses como estudante de Direito, quando, em setembro de 1950, tornou-se redator-chefe da recém-gestada Revista Ângulos, vinculada ao Centro Acadêmico Ruy Barbosa, registrando a sua marca logo no primeiro volume do periódico, com a inclusão do artigo A llustração, ao lado de ensaios produzidos por Orlando Gomes, Garcia Lorca, Murilo Mendes, dentre outros grandes intelectuais daquele tempo.

O envolvimento com a Revista Ângulos propiciou-lhe combustível teórico e ânimo crescente para o desenvolvimento das suas produções textuais, de modo que, em 1952, aos 21 anos e ainda enquanto estudante de Direito, Machado Neto publicou a sua primeira obra na área da Sociologia do Conhecimento, intitulada Dois Aspectos da Sociologia do Conhecimento, tendo por referencial as perspectivas teóricas Karl Marx e Karl Manhheim, obra esta merecedora de uma menção honrosa do Instituto Brasileiro de Filosofia (Modesto, 1998, p. 57).

À época da sua vida universitária, vivia-se no Brasil período de grande efervescência ideológica, marcado pelo surgimento de movimentos estudantis que carregavam bandeiras diversas, e a aurora do período de redemocratização do País, recém-egresso do primeiro período ditatorial, ainda sob a égide da Constituição, de 1946. Dessarte, o seu envolvimento com debates políticos e ideológicos tornou-se inevitável (Modesto, 1998, p. 56). 
Tal como suas atividades e produções acadêmicas vinham sinalizando, ao seu bacharelado em Direito, em 1953 (este alcançado com diploma de Honra ao Mérito, insta destacar), sucedeu o seu ingresso no magistério, a despeito da prática advocatícia, campo que a muitos contemporâneos pareceu mais atrativo. Neste mesmo ano, foi aprovado em concurso para professor-assistente de Filosofia no Colégio Central, aquele que outrora acolheu as inquietações do jovem Machado Neto, tendo ali a oportunidade de conviver e influenciar alunos notáveis, a exemplo de Gláuber Rocha (Muricy, 1996, p. I 18). Logo em seguida, em paralelo às suas atividades no magistério, decidiu por empreender novo ingresso na UFBA, na condição de acadêmico do curso de Ciências Sociais da Faculdade de Filosofia.

Machado Neto assumia, pois, como bem aponta sua esposa Zahidé Machado Neto (1979), a sua condição de homo theoreticus, tornando-se um intelectual de ofício, dedicado exclusivamente ao universo acadêmico.

Em sua passagem pelo magistério universitário, colecionou cátedras na Universidade Federal da Bahia - Faculdades de Direito e de Filosofia - no Instituto Superior de Estudos Brasileiros, na Faculdade de Direito da Universidade de Alagoas. No entanto, foi na Universidade de Brasília (UnB), instituição que ajudou a fundar, que experienciou a turbulência que viria a culminar no seu expurgo político.

Em 1961, a convite de Heron de Alencar, Machado Neto subscreveu o projeto conceptivo da UnB, ao lado de Darcy Ribeiro, Anísio Teixeira, sua esposa Zahidé e Carlos Costa, assumindo o projeto de implementação didática da disciplina Teoria Geral do Direito, sem prejuízo das suas atribuições administrativas de Chefia do Instituto de Ciências Humanas, com a ingente missão de elevar aquela academia aos padrões internacionais de cultura, tornando-a modelo vanguardista. Decerto, tarefa árdua, porém absolutamente concretizável, considerando o seu dinamismo e empenho (Neto, 1979).

Entrementes, em 9 de abril de 1964, decorridos nove dias do golpe militar que instaurou o segundo período ditatorial no País, com a ocupação do campus daquela universidade por policiais armados e tropas do exército, inciava-se talvez o maior de seus desafios à frente da UnB. Acusados de subversivos, alunos e professores foram perseguidos, instalações foram revistadas e interditadas, culminando na exoneração de onze professores, até mesmo a do então reitor, Anísio Teixeira. $\bigcirc$ desenvolvimento intelectual, para o regime militar, parecia tornar-se uma ameaça iminente' .

\footnotetext{
' Não sem motivo a afirmação de Viviane Forrester (1997, p. 68), aduzida em contexto diverso, todavia absolutamente aplicável à situação em comento: "Porque não há nada mais mobilizador que o pensamento. [...] Não existe atividade mais subversiva do que ele. Mais temida. Mais difamada. E isto não se deve ao acaso: o pensamento é político. Daí a luta insidiosa, cada vez mais eficaz, hoje mais do que nunca, contra o pensamento. Contra a capacidade de pensar."
} 
Tentou opor resistência à opressão que ora se instaurava, chegando a encontrar-se com o presidente Castelo Branco, para diálogo. As tentativas restaram, contudo, infrutíferas, de modo que, em outubro de 1965, viu-se excluído da universidade que ajudou a edificar (Neto, 1979).

Exilado, retornou à Bahia nos idos de 1965, concentrando-se então na elaboração de obras analíticas da situação vivenciada à frente da UnB, tal como o trabalho intitulado A Ex-Universidade de Brasília - Significação e Crise.

Em 1968, a convite de Roberto Santos, então reitor da Universidade Federal da Bahia, recebeu a incumbência de implantar o curso de Pós-Graduação Stricto Sensu na área das Ciências Humanas, assumindo desde a elaboração do projeto até a efetiva direção do Mestrado em Ciências Humanas, curso que se notabilizou pela excelência acadêmica, congregando uma plêiade de intelectuais de renome mundial.

Em 1973, produziu a famosa Tese Fundamentação Egológica da Teoria Geral do Direito, por ocasião do concurso para professor titular do Departamento de Direito Público, posteriormente publicada na Argentina pela Editora da Universidade de Buenos Aires, por indicação do ali professor Carlos Cossio, de quem nutria profundo respeito e obtinha inspiração teórica.

Em 17 de julho de 1977, aos 47 anos, vítima de um infarto do miocárdio, faleceu em Salvador, deixando órfãos os seus dois filhos - Carlos Frederico e Luis Antônio - e os inúmeros alunos que fitavam a sua figura como um prestimoso mestre e amigo.

Sua carreira foi assim interrompida de forma precoce e paradoxalmente madura, após obter duas Graduações - em Direito e em Ciências Sociais - dois doutoramentos na forma de concursos à Livre Docência - em Direito e Sociologia - e os cargos de professor titular da Universidade Federal da Bahia - em Teoria Geral do Direito e em Sociologia - tendo logrado êxito nos respectivos concursos públicos para seleção.

balanço de sua vida acadêmica pode ser inferido da análise do acervo composto por trinta e dois livros, oitenta e nove ensaios publicados em periódicos nacionais e estrangeiros, além de inúmeras resenhas e separatas, produções nos mais diversos campos do saber, desde Política, Filosofia, Sociologia do Conhecimento, Direito, Economia Regional e mesmo Crítica Literária, cabendo especial destaque para: Para uma Sociologia do Direito Natural ( 1958), Teoria do Direito e Sociologia do Conhecimento ( 1 965), Compêndio de Introdução à Ciência do Direito ( 1973), Fundamentación Egológica de la Teoria General del Derecho (1974), Debate sobre a Teoria Egológica como Teoria Geral do Direito (1974). Tais obras, como bússolas, orientam os primeiros tateares dos iniciados no complexo universo jurídico ${ }^{2}$.

${ }^{2}$ Obras, títulos acadêmicos e rol de atividades docentes e profissionais desempenhadas pelo jusfilosófo podem ser encontrados curriculum vitae disponível no Memorial A. L. Machado Neto, mantido por seu filho, Carlos Frederico Machado Neto: http://www.mbaf.com.br/memorial_hom.asp 
Ao longo de sua trajetória intelectual, pode ser enxergado o desenvolvimento vigoroso de uma produção diversificada nos mais diversos campos do conhecimento. Não obstante, sua indelével contribuição à ciência jurídica repousa, sobretudo, na importação para solo pátrio da Teoria Egológica do Direito, criada pelo jusfilósofo argentino Carlos Cossio, como alternativa a até então tradicional teoria positivista, de matriz kelseniana, que ele julgava inadequada do ponto de vista epistemológico ${ }^{3}$.

\section{CONTORNOS GERAIS DA TEORIA EGOLÓGICA DO DIREITO DE CARLOS COSSIO}

A Teoria Egológica do Direito, cunhada por Carlos Cossio, juntamente com a Teoria Tridimensional, esta da lavra do igualmente erudito Miguel Reale, conformou o culturalismo jurídico na América Latina, enquanto vertente de pensamento surgida no seio dos movimentos pós-positivistas.

Com efeito, pretendia-se superar a compreensão do Direito como um produto metódico de procedimentos formais, dedutivos e indutivos, para afirmá-lo uma unidade imanente, de base concreta e real, que repousa sobre valorações, concebendo-o, dessarte, como objeto criado pelo homem, sendo, pois, pertencente ao campo da cultura (Soares, 2012, p. 209).

Em realidade, memora Frederico Pensado (2008, p.85), a compreensão do Direito como um produto cultural já era objeto dos estudos do alemão Gustav Radbruch, desde 19|4. No entanto, é a partir de 1941, com a publicação da obra de Cossio, La valoración jurídica y la ciencia del derecho, que tal debate jusfilosófico ganha inegável fôlego.

Partindo da classificação dos objetos, nos moldes propostos por Edmund Husserl, Cossio define com clareza a posição do Direito como um objeto cultural e, em especial, um objeto egológico, lastreado na conduta humana em sua interferência intersubjetiva.

Segundo Husserl, toda ciência está voltada para a análise de objetos, sujeitando-se às leis inerentes às suas respectivas essências:

A toda ciência corresponde um domínio de objetos como domínio de suas investigações, e a todos os seus conhecimentos, isto é, aqui a todos os seus enunciados corretos correspondem, como fontes originárias da fundação que atesta a legitimidade deles, certas intuições nas quais há doação dos próprios objetos desse domínio ou, ao menos parcialmente, doação originária deles [...]. $\bigcirc$ mundo é o

\footnotetext{
${ }^{3}$ Para maior imersão no tema, sugere-se leitura de ensaio de Machado Neto intitulado, Notas sobre a insuficiência da teoria geral do direito em uso ( 197 I), disponível na página eletrônica do Memorial A.L.Machado Neto: http://www.mbaf.com.br/memorial_hom.asp
} 
conjunto completo dos objetos da experiência possível e do conhecimento possível da experiência, dos objetos passíveis de ser conhecidos com base em experiências atuais do pensamento teórico correto (2006, p. 9).

Husserl, à ocasião da elaboração das bases teóricas da sua fenomenologia existencial, cuidou de catalogar os objetos de pesquisa em quatro categorias, observadas as suas peculiaridades ônticas, a saber: objetos ideais, naturais, culturais e metafísicos.

Os objetos ideais seriam aqueles objetos sem existência, neutros de valor, situados no plano ideológico, fundados em juízos apodíticos e compreendidos a partir de processo intelectivo em que se é adotado o método dedutivo de progênie cartesiana.

De outro modo, os objetos naturais seriam aqueles objetos reais e neutros de valor, podendo ser apreendidos por meio de processo explicativo, a partir do emprego de método empírico-indutivo;

A seu turno, os objetos culturais se afigurariam como objetos reais - estando, portanto, no plano da experiência - e passíveis de serem valorados positiva ou negativamente. Sua compreensão seria viabilizada pela adoção do método empíricodialético.

Por fim, na categoria dos objetos metafísicos, estariam situados aqueles que, embora reais e passíveis de valoração, não se encontrariam no plano empírico (Machado Neto, 1988, p. 21 ).

Nessa esteira de entendimento, a heterogeneidade dos objetos justifica a pluradidade de métodos a serem adotados com vista à realização do conhecimento. Em mais simples termos, pretendendo-se compreender plenamente determinado objeto, a identificação dos traços caracterizadores da sua essência - ou eidos, empregando expressão husserliana - é etapa fundamental à adequada eleição do método a ser empregado na análise.

Nesse diapasão, leciona Cossio acerca da adequada eleição dos métodos de estudo de um objeto:

[...] Si cada método adjudica a la misma ley una significación diferente, entonces cabe preguntar: ? En base de qué criterio se ha de optar por un método u otro? [...] el problema que hemos esbozado se resuelve dando a cada método interpretativo su esfera de legitimidad, no se puede volver la espalda a la Exegesis en forma absoluta; antes por el contrario la Exegesis conserva su valor en la esfera que le es propria. (1987, p. 2-4)

Por sua vez, Carlos Cossio transcende os limites da teoria dos objetos husserliana quando, ao direcionar seu estudo aos objetos culturais, identifica na composição destes a presença de um substrato e um sentido. 
O substrato representa o suporte fático, e pode equivaler a um objeto mundanal um elemento da realidade física - ou um objeto egológico - uma conduta humana. $\bigcirc$ sentido, por sua vez, reflete o juízo de valor realizado pelo sujeito-intérprete acerca do suporte fático, qualificando-o.

Tomando por empréstimo o exemplo lançado pelo próprio autor argentino, podese perceber com clareza a configuração dos elementos retro apontados a partir da análise da estátua da Vênus de Milo, exibida no Museu do Louvre. A significação da estátua como obra de arte depende da atribuição de um valor - no caso, a beleza - ao objeto mundanal - a peça de mármore esculpida. Inexistindo tal valoração, subsistiria, apenas, uma peça de mármore. Em outros termos, o objeto Vênus de Milo é produto (e, portanto, resultado) de uma valoração realizada por um intérprete sobre determinada fração da realidade.

Passando-se ao exame do Direito, sustenta Cossio que, com vista à consecução de uma adequada teoria jusfilosófica, a apreensão da essência do direito - e, portanto, da categoria de objetos a que está imbricado - faz-se primordial a eleição do correto método para seu estudo. Para o autor argentino, não seria a exegese literal o adequado modo de pensar as relações e implicações normativas ( 1 987, p. 4).

Ao tratar do Direito, posicionando-o dentre os elementos culturais, Cossio (1948, p. 70) afirma-o composto por um substrato, qual seja, a conduta humana, e um sentido, ou seja, um juízo de valor incidente sobre a conduta humana objeto de avaliação. Temse, portanto, a norma jurídica como produto da sobreposição do sentido sobre o suporte fático, da valoração sobre o comportamento. Daí resulta, portanto, que a conduta, à luz da teoria egológica, desponta como elemento constitutivo do próprio Direito.

Com base nessa construção teórica, Cossio sustenta o deslocamento do objeto do estudo do epistemológico do Direito da norma para a conduta humana. Isso sucede porque o objeto da ciência do Direito não é a norma em si, mas o seu significado, elaborado a partir da valoração de uma conduta. Eis que a norma jurídica deflui do relacionamento entre os seus elementos, a saber, substrato e sentido, valoração e conduta. ( 1948, p. 7I)

A conduta, portanto, é tida como elemento conformador da norma jurídica, não como mera finalidade normativa.

Dessarte, é incorreto pensar a norma como criação legislativa autônoma, produto da ratio do legislador, voltada a impactar a conduta humana.

Sobre o tema, cumpre transcrever a lição de Cossio:

Aquí nos urge precisar las cosas. Los juristas dicen tambíen que el Derecho tiene por objeto la conducta, usando la palabra "objeto" en el sentido de "propósito" o "destino". Pero ninguna sinonimia cabe entre la conducta como propósito o destino del Derecho y la conducta como substrato del Derecho. (1948, p. 70) 
A despeito do posicionamento presente na teoria tradicional, em que a norma jurídica é criada com o escopo de direcionamento da conduta do agente social, sob a ameaça de imposição de uma sanção, à luz da teoria egológica, à medida que se apresenta como elemento constitutivo da norma, a conduta humana passa a integrar o próprio Direito. Em simples termos, a proposta egologista revela-se no sentido de, em lugar de primeiro pensar uma norma ideal, voltada a conformar uma conduta, primeiro analisar a conduta, no âmbito da tríade espaço-tempo-valoração, para, posteriormente, como decorrência natural, inferir a norma jurídica exsurgente. Assim, pretende-se inferir uma norma jurídica autêntica, uma vez analisada a valoração exercida sobre a conduta.

Não suficiente, considerando-se que a valoração, seja positiva ou negativa, sobre a conduta é realizada por outro sujeito, à medida que é afetado - ou se encontra em vias de ser afetado - pela dita conduta, tem-se, em realidade, a necessidade da análise da conduta humana em interferência intersubjetiva.

Para Cossio (1948, p. 72), a existência humana é, em realidade, coexistência. $\bigcirc$ Direito é sedimentado a partir de relações de contraste e alteridade, havendo recíproca articulação entre direitos e deveres dos sujeitos envolvidos em uma dada relação jurídica. É nessa bilateralidade que repousa o objeto do conhecimento jurídico.

Ao passo que as relações intersubjetivas são travadas guardando adstrição a balizas éticas postas pela sociedade em determinado momento histórico, a construção do sentido atribuído à conduta é realizada sobre valores positivados em dado espaçotempo, valores tais que o autor argentino cuidou de agrupar, afirmando-os conexos. $\bigcirc$ plexo axiológico cossiano é composto pelos seguintes valores, próprios das sociedades: justiça, solidariedade, paz, poder, segurança e ordem (Cossio, 1987, p. 8I-83).

Assim, as determinações normativas criadas pelo legislador devem espelhar os valores que permeiam a realidade social, atentando, nessa empresa, para as relações intersubjetivas travadas no contexto comunitário.

A partir de tal percepção, como assentado em linhas anteriores, Cossio sustenta suas críticas à teoria kelseniana, em especial no que atine à metódica constituída sobre um nexo lógico de imputação em que a resposta jurídica é obtida a partir da vinculação a premissas impostas pelo legislador, sustentando que, para que a experiência jurídica possa ser compreendida em sua plenitude, não deve ser o Direito tido como um deverser neutro, mas um dever-ser associado aos valores que permeiam o mundo real, de modo que entre ser e dever-ser subsista uma constante comunicação dialética, denominada pelo autor de Círculo Hermenêutico (Cossio, 1948, p. 74-75).

\section{A TEORIA EGOLÓGICA DO DIREITO E AS CONTRIBUIÇÕES DE A. L. MACHADONETO}

Deveras, Machado Neto (1972, p. 152) creditava à teoria egológica um caráter instrumental, ao afirmá-la um "petrechamento teórico para instrumentar a atividade 
pragmática do jurista". Sua proposta era a superação do hiato existente entre teoria e práxis, cunhando uma teoria mais compatível com a ideia de realidade conformadora da normatividade e, portanto, de uma teoria do Direito apta a superar as inadequações que pairavam a teoria tradicional até então dominante.

Na esteira do pensamento de Carlos Cossio, Machado Neto refutava, em absoluto, a concepção imperativista das normas, e a compreensão destas como uma ordem emanada prevalentemente do Estado.

Para ele, o normativismo lógico, característico do pensamento kelseniano, necessitava de uma superação paradigmática, a fim de romper com a identificação do Direito como uma ordem estritamente legislativa e, portanto, centrada na figura do legislador. Para tanto, cuidou de demonstrar a existência de círculo vicioso relacionado aos limites existenciais da norma:

De fato, qual a resposta de Kelsen à pergunta sobre por que uma norma é positiva? Sua resposta será: porque foi posta pelo órgão competente.

Mas, se agora indagamos por que o órgão é competente, a resposta será a própria revelação do círculo vicioso: - porque foi criado segundo a norma positiva que lhe deu tal competência. O problema da positividade simplesmente não é problema para a teoria egológica. A conduta é, de si, positiva porque é um fato, embora humano e, pois, significativo. Não há que perguntar, pois, pela positividade do direito, uma vez que se direito é conduta e conduta é fato, a própria expressão direito positivo já é pleonástica. O que cabe perguntar é se determinada norma é positiva ou não conforme ela logre conceituar a conduta existente em dada comunidade ou não. Se logra, é uma norma verdadeira, se não, é um pensamento normativo que não logra conceituar convenientemente seu objeto - a conduta em interferência intersubjetiva (1972, p. I 58).

De acordo com a perspectiva machadiana, o Direito não deve ser tido como objeto hermético e autônomo, dissociado da realidade e legitimado por uma ordem formal, mas, na condição de objeto cultural, deve ser elástico no sentido de viabilizar a intersecção necessária entre o ser e o dever-ser.

Desse modo, o legislador e o operador do Direito devem ter em vista os padrões de conduta existentes na sociedade quando da elaboração e aplicação da norma, uma vez que o direito, fruto da convivência humana em sociedade, "havia de trazer a marca do ambiente que o forma e onde ele exerce a sua função socializadora" (Machado Neto, 1988, p.73).

Ao depreender a intrínseca relação entre o Direito e a Facticidade, uma leitura sob o enfoque cultural conduz à afirmação de que o Direito encontra sua matriz de validade na realidade social, não sendo mero produto da razão. A realidade social plasma o Direito, 
outorgando às normas a legitimação necessária à validade plena do ordenamento jurídico.

Com o fito de apresentar a distinção fundamental do direito para com os demais instrumentos coatores de controle social, dentre os quais se situam os folkways - normas do trato -, normas morais e normas religiosas, Machado Neto ratifica a afirmação cossiana no sentido de ser o direito objetivo uma "menção normativa que interpreta a conduta humana em termos de um contínuo de licitudes e um descontínuo de ilicitudes" (Machado Neto, 1988, p. 88).

Adotando a premissa de que difere a norma jurídica das demais normas de controle social, ante a possibilidade de determinar-se, como sanção, a execução forçosa, Machado Neto conclui que tal possibilidade está indissociavelmente vinculada à bilateralidade da norma jurídica e, por conseguinte, à existência de um direito subjetivo oponível por outro indivíduo direta ou indiretamente afetado pela ação, o que não ocorre nas demais hipóteses de normas de controle social:

É que se A tem um dever de polidez para com B, a sociedade não reconhece a $\mathrm{B}$ um direito de exigir essa polidez desejável por parte de A. Apenas se limita a punir A com a sanção difusa da opinião pública e, nem por isso, B logrou desfrutar da cortesia que A lhe devia. Ora, isso prova que é da própria bilateralidade essencial do direito que advém a sua exigibilidade por parte do titular do direito subjetivo e, daí, a característica da sanção jurídica como imposição inexorável ou execução forçosa (Machado Neto, 1988, p.87).

Segundo o autor, as ações ocorridas no âmbito das normas extrajurídicas de controle social - aquelas cuja execução forçosa em resposta a inobservância não se faz

\footnotetext{
${ }^{4}$ Há de ser consignada ressalva de que o termo "validade" não foi empregado por Machado Neto, tendo este optado pela adoção da expressão "norma verdadeira" (1972, p. I 58). Percebe-se, não obstante, a proximidade das ideias de Machado Neto ora reproduzidas àquela definição outrora apresentada por Jürgen Habermas quando da análise da validade social das normas do Direito, na obra Direito e democracia: entre facticidade e validade. Segundo o filósofo, a adequada compreensão do moderno Estado de Direito pressupõe uma aproximação dialética da realidade social (ser) com a previsão normativa (dever-ser), em oposição a uma reflexão puramente racionalista-normativa (Habermas, 1997, p. 47). A teoria egológica, leciona Muricy (1997- 1998, p. 84), incorpora o emprego do termo verdade jurídica, referindo-se a uma "verdade estimativa, cujo critério positivo é a valoração judicial. Não basta, diz Cossio, a sintonia do juiz com as regras de coerência do sistema, [...] além de coerente, para ser justa a decisão deve representar a melhor leitura judicial do entendimento societário em dado momento, vale dizer o melhor equacionamento possível dos valores condensados no ordenamento."
} 
possível - implicam, para a ordem jurídica, comportamentos facultados e não proibidos. Conclui, dessarte, inexistir conduta indiferente para o Direito, porquanto toda conduta incidirá na esfera do ilícito ou do lícito ou juridicamente facultado ( 1972, p. I 54). ${ }^{5}$

Nesse sentido, Machado Neto logra êxito ao apartar o Direito da Moral, no que tange aos seus efeitos, inobstante os considere manifestações da normatividade ética. Todavia, apesar de tal evidente distinção, o relacionamento entre Direito e Moral é imperioso, ao considerar que "uma sociedade passa a conferir a nota de exibilidade e a consequente imposição inexorável através da sanção organizada a toda exigência moral que se tenha tornado essencial à vida e ao equilíbrio do grupo" (Machado Neto, 1988, p. 92).

Noutras palavras, das lições de Machado Neto pode-se extrair que nem toda exigência moral corresponderá a uma norma do Direito. Todavia, toda norma do Direito que se pretenda "verdadeira" deverá refletir uma exigência moral vigente na sociedade em tal período. Isso, pois, em termos seus, "pode ser dito que o direito, ou melhor, que o proibido pela ordem jurídica é atribuição de elegibilidade que a sociedade confere àquele mínimo de moral que ela considera imprescindível à sua sobrevivência" (Machado Neto, 1988, p. 92).

Assim, ao perceber que o Direito, em movimento dialético, condiciona - a partir de mecanismos coercitivos, em especial da sanção e da execução forçada - e, de forma recíproca, é condicionado pela realidade social, refletindo valores existentes em um dado espaço-tempo, Machado Neto demonstra a incoerência ao se aplicar o princípio da neutralidade axiológica, típico das ciências naturais, ao estudo do Direito (1988, p. 13).

Tal compreensão abrange não somente a atividade normativa legislativa. Ao transpor o objeto da tarefa de interpretação do jurista da norma para a conduta, e compreendendo esta última como comportamento acrescido de significação fundada num valor atrelado a um contexto histórico-social, Machado Neto lança subsídios para orientar a tarefa do jurista prático, em especial dos magistrados, à adequada aplicação do Direito. (Muricy, 1997/1998, p. 81 ).

Focando a atenção no produto máximo da atividade judicante, a sentença adequada seria, sob o prisma da motivação dos fundamentos, a aproximação dos valores que impulsionaram a decisão ao plexo axiológico da sociedade. Refere-se, portanto, à fenomenologia da sentença, proposta por Cossio. Registra, todavia, importante ressalva, ao discorrer sobre as instâncias de normatividade, no que atine à importância das fontes do Direito, em especial a norma positivada, como estruturas balizadoras da

${ }^{5}$ À luz da tradicional teoria combatida por Machado Neto, interessava à norma jurídica apenas a conduta ilícita. 
atividade judicante, voltadas a evitar o arbítrio do julgador.

Se a avaliação ou conceituação jurídica da conduta fosse livre, o aplicador ou o julgador estabeleceria a norma mediante a qual julgaria a conduta. Tal sistema representaria a absoluta insegurança vital, pois é fato notório a diversidade dos juízes sobre a conduta. Assim, o mesmo fato de conduta seria diversamente julgado e, pois, juridicamente conceituado conforme o tipo psicológico, as opiniões e as ideologias dos julgadores. Urge, portanto, que a valoração judicial esteja limitada por instâncias objetivas de valoração. (Machado Neto, 1988, p.197)

Com efeito, reconhece o jusfilósofo, por óbvio, a suma importância da lei, dentre as balizas normativas, não sem admitir, contudo, a importância do costume como fonte do Direito, mencionando até mesmo a legitimidade do costume contra legem como argumento passível de adoção pelo magistrado à guisa de fundamentar o processo decisório, em hipóteses em que falta à lei positivada a adequação ao contexto social.

Por derradeiro, cumpre frisar que Machado Neto entendia o Direito como um objeto cultural, pelo que a compreensão seria o ato gnosiológico aplicável ao seu estudo. A metodologia adequada à realização de tal compreensão seria o método empírico-dialético: empírico, porquanto indissociável da realidade espaço-temporal, e dialético, em razão da necessidade de permanente interlocução entre substrato e sentido (Machado Neto, 1988, p. 222).

\section{CONSIDERAÇÕES FINAIS}

Sintetizar a premissas teóricas de um autor com tão vasta bibliografia é, seguramente, tarefa temerária, porquanto subsista o alto risco de incorrer em reducionismos. Preferível, nessa empresa, sugerir ao leitor interessado a consulta àquela que pode ser considerada uma obra-síntese, Um novo cogito e sessenta verdades básicas para uma eidética do social ( 1977), em que, pela utilização de estrutura de aforismos, Machado Neto apresenta um extrato das ideias centrais que concatenam a sua matriz teórica:

Segundo ele, "há dois tipos de objetos culturais - mundanais e egológicos conforme tenham por substrato um pedaço da natureza ou um momento do ego pessoal de alguém, respectivamente", afirma a $4^{a}$ Verdade; "A conduta (vida biográfica) é liberdade metafísica fenomenizada", registra a I $8^{a}$ Verdade. "Direito é a interferência intersubjetiva de condutas (meu fazer e o impedir, ou não, dos outros sujeitos conviventes)"; "Os modos de ser do direito são quatro e apenas quatro: faculdade, prestação, ilícito, sanção"; "A análise da experiência (qualquer, trata-se de objeto cultural, egológico ou mundanal) revela-nos necessariamente os seguintes elementos: a) uma estrutura lógica (normativa): elemento formal e a priori. b) uma valoração: elemento 
material e a priori. c) um conteúdo histórico-condicionado: elemento material e a posteriori. Daí que todo objeto cultural e a moral - sejam: a) norma; b) valor; c) fato", revelam, respectivamente, as $20^{\mathrm{a}}, 21^{\mathrm{a}}$ e $22^{\mathrm{a}}$ Verdades.

Dizia ainda Machado Neto (1977, p. 268) que "o homem não tem natureza, mas história" e, "a vida não nos é dada feita, mas a fazer. A vida é fazer". Pois bem. Machado Neto fez história. Ea fez de forma notável.

Prestimosas foram as suas contribuições acadêmicas. Na ocasião em que o pensamento vigente nos centros intelectuais brasileiros era reflexo de lições europeias, Machado Neto demonstrou audácia intelectual e firmeza de caráter, ao importar, para as salas de debates baianas, as valiosas lições de um jus filósofo argentino, tornando-se seu principal difusor em solo pátrio.

Em oposição ao que nominava pensamento tradicional - o positivismo lógico kelseniano cuidou de lançar bases para a sedimentação de uma nova hermenêutica, lastreada não mais na lógica formal, em que o objeto de interpretação repousa na norma, mas numa lógica transcendental, em que o foco é deslocado para a conduta humana - sempre compreendida como conduta compartida ou em interferência intersubjetiva. Não o fez, contudo, sem antes construir solidamente premissas aptas a justificar a aproximação entre o Direito e os influxos sociais, conferindo ao primeiro uma indissociável carga axiológica. Seu êxito, pode-se supor, repousa na sua íntima vinculação e fascínio pela Sociologia.

Seu empenho de transformar a Universidade Federal da Bahia numa instituição modelar rendeu-lhe o respeito e veneração de mestres e estudantes de inúmeras gerações, até daqueles que nem sequer chegaram a desfrutar do seu convívio, mas conheceram o seu legado intelectual. Não sem motivo é que a Faculdade de Direito da Universidade Federal da Bahia carrega o seu nome em seu pórtico, como justa homenagem ao emérito Mestre que a ela tanto se dedicou.

Como bem afirmou Marília Muricy, "o vigor de uma instituição mede-se - entre outros indicadores - pela capacidade que revela de manter viva a sua memória" ( I996, p. | | 5).

Justo, portanto, que homenagens sejam rendidas àquele que jamais deixou de envidar esforços no sentido de transformar a Universidade Federal da Bahia - aquela que lhe serviu de berço - num Centro de Excelência Jurídica do Brasil e da América Latina.

\section{REFERÊNCIAS}

COSSIO, Carlos. La Valoración Jurídica y la Ciencia del Derecho. Buenos Aires: Arayu, 1987.

. Panorama de la teoria egologica del derecho. Revista Trimestral de Cultura Moderna. Universidad Nacional de Colombia. Bogotá, p.67-94, 1948. Disponível em: <http://carloscossio.com.ar/wp-content/uploads/2013/03/1948_panorama.pdf> 
Acesso em 7 set. 2015 .

FORRESTER, Viviane. O horror econômico. Trad. Álvaro Lorencini. São Paulo: Editora da Universidade Estadual Paulista, 1997.

GUSDORF, Georges. Professores, para quê? Lisboa: Morais, 1970.

HABERMAS, Jürgen. Direito e Democracia: entre faticidade e validade. Trad. Flávio Beno Siebeneichler. Rio de Janeiro: Tempo Brasileiro, 1997.

HUSSERL, Edmund. Idéias para uma fenomenologia pura e para uma filosofia fenomenológica. São Paulo: Idéias e Letras, 2006.

MACHADO NETO, A.L. Compêndio de introdução à ciência do direito. São Paulo: Saraiva, 1988.

.Direito, cultura e existência (ou sobre a instrumentalidade da teoria egológica do direito. Revista de Informação Legislativa. [S.I.] v. 9, n. 36, p. 149-164, out./dez. I 972 Disponível e m : <http://www2.senado.leg.br/bdsf/bitstream/handle/id// 80589/000345 I 97.pdf?sequ ence $=\mathrm{I}>$ Acesso em 8 set. 2015 .

. Notas sobre a insuficiência da teoria Geral do direito em Uso. Revista brasileira de filosofia. São Paulo, $n^{\circ}$. 84, 1971. Disponível em: <http://www.mbaf.com.br/memorial_pub.asp?id=2> Acesso em 6 set. 2015.

Um novo cogito e sessenta verdades básicas para uma eidética do social. Revista de Ciências Sociais. Fortaleza, v.8, n.l/2, 1977. Disponível em: <http://www.repositorio.ufc.br/handle/riufc/9780> Acesso em I6 set. 2015.

MODESTO, Paulo. Pronunciamento sobre a vida e obra de A. L. Machado Neto. Revista do CEPEJ. Salvador, v.0 I, p. 67, 1988.

NETO, Zahidé Machado. A. L Machado Neto - Vida intelectual: vida, paixão e morte. Salvador, 1979 . Disponível e m <http://www.mbaf.com.br/memorial_pub.asp?id=I> Acesso em 7 set. 2015.

PENSADO, Frederico. O objeto do direito do ponto de vista da fenomenologia egológica. Cadernos da EMARF: Fenomenologia e Direito. Rio de Janeiro, v. I, n. I, p. I - I 00 , abr./set. 2008 . Disponível e m: <http://www.sfjp.ifcs.ufrj.br/revista/downloads/o_objeto\%20do\%20direito.pdf> 
Acesso em 16 set. 2015.

PINTO, Marília M. M. Machado Neto. Discurso proferido no são nobre da Reitoria, em 22 de novembro de 1998, por ocasião da homenagem póstuma ao prof. Machado Neto. Revista da Faculdade de Direito da UFBA, Salvador, v.37, p. 80, 1996.

Pensamento Filosófico de A. L. Machado Neto e a Nova Hermenêutica Jurídica. Revista da Faculdade de Direito da UFBA, Salvador, v.37, p. 69-9I, 1997 1998.

SOARES, Ricardo Maurício Freire. Curso de introdução ao estudo do direito. $3^{\mathrm{a}}$ ed. Salvador: Jus Podivm, 2012.

Recebido em: 14/06/2017

Aprovado em: 12/07/2017 